\title{
Parâmetros morfofisiológicos testiculares de camundongos (Mus musculus) suplementados com geleia real
}

\author{
[Morphophysiological parameters of mice (Mus musculus) testicles supplemented \\ with royal jelly] \\ A.C.T. Morais ${ }^{1}$, L.P. Barbosa ${ }^{2 *}$, M.M. Neves ${ }^{3}$, S.L.P. Matta ${ }^{1}$, D.B. Morais ${ }^{1}$, B.E.S. Melo ${ }^{3}$ \\ ${ }^{1}$ Universidade Federal de Viçosa - Viçosa, MG \\ ${ }^{2}$ Departamento de Produção Animal - UFBA \\ Av. Ademar de Barros, 500 \\ 40170-110 - Salvador, BA \\ ${ }^{3}$ Centro Universitário do Leste de Minas Gerais - Coronel Fabriciano, MG
}

\section{RESUMO}

Avaliaram-se os efeitos da geleia real sobre os parâmetros morfofisiológicos testiculares de camundongos (Mus musculus). Utilizaram-se 57 machos Swiss, com quatro meses de idade, distribuídos aleatoriamente em seis tratamentos: $\mathrm{T} 1$ : solução fisiológica, via intraperitoneal; $\mathrm{T} 2: 0,1 \mathrm{mg}$ de geleia real, via intraperitoneal; T3: $0,2 \mathrm{mg}$ de geleia real, via intraperitoneal; T4: água destilada, via oral; T5: 0,1mg de geleia real, via oral; e T6: 0,2mg de geleia real, via oral. Após 45 dias de suplementação com geleia real, os animais sacrificados e pesados tiveram seus testículos coletados, incluídos em parafina e corados com hematoxilina/eosina. Não houve diferença entre os tratamentos quanto aos: pesos corporal e testicular, índice gonadossomático, diâmetro tubular, altura do epitélio, comprimento total dos túbulos seminíferos, comprimento tubular por grama de testículo, índices tubulossomático e leydigossomático e valores de proporção volumétrica referentes à túnica própria, epitélio seminífero, vaso sanguíneo e vaso linfático. Foi encontrada diferença entre T1 e T3 em relação aos túbulos seminíferos e ao espaço intertubular.

Palavras-chave: camundongo, Mus musculus, geleia real, testículo, morfometria

\section{ABSTRACT}

The effects of royal jelly on the morphophysiological parameters of mice (Mus musculus) testicles were studied. Fifty-eight male Swiss mice were evaluated. They were four-month old and were randomly distributed in six treatments: T1: physiological solution, intraperitonial route; T2: 0.1mg of royal jelly, intraperitonial route; T3: $0.2 \mathrm{mg}$ of royal jelly, intraperitonial route; T4: distilled water, orally; T5: $0.1 \mathrm{mg}$ of royal jelly, orally; and T6: $0.2 \mathrm{mg}$ of royal jelly, orally. After 45 days of supplementation with royal jelly, the animals were weighted, slaughtered, and the testicles collected, included in paraffin, and stained with haematoxylin-eosin. No differences among treatments were observed for: body and testicular weights, gonadossomatic index, tubular diameter, epithelial height, total length of seminiferous tubules, tubular length per testicle gram, tubulossomatic and leydigossomatic indexes and the value of volumetric proportion related to tunic, seminiferous epithelium, blood vessel, and lymphatic vessel. Differences between $T 1$ and T3 about the seminiferous tubules and intertubular space were found.

Keywords: mice, Mus musculus, royal jelly, testicle, morphometry

\section{INTRODUÇ̃̃O}

Nos últimos anos, é perceptível um interesse maior pelos produtos apícolas, não somente o mel, mas também outros produtos fornecidos pelas abelhas tais como: pólen, própolis, geleia real, apitoxina, cera, larvas, pão de abelhas, opérculos e mel de melato. Esse interesse é

Recebido em 2 de julho de 2008

Aceito em 15 de dezembro de 2008

*Autor para correspondência (corresponding author)

E-mail:1pires73@yahoo.com.br 
justificado pelo fato de esses produtos apresentarem propriedades medicinais e nutritivas singulares (Lengler, 1999).

A geleia real é uma substância produzida e secretada pelas glândulas mandibulares hipofaríngeas das abelhas operárias jovens, denominadas nutrizes, entre o quinto e o $14^{\circ}$ dia de vida (Puttkammer, 1994). Essa substância possui complexa composição de proteínas, aminoácidos, ácidos orgânicos, hormônios esteroides, fenóis, açúcares, minerais (Pamplona et al., 2004), vitaminas e outros componentes ainda não identificados (Kohno et al., 2004).

Os efeitos produzidos na abelha rainha, relacionados à longevidade e à fertilidade, devido ao fato de sua dieta ser rica em geleia real, têm despertado interesse em pessoas que acreditam na produção de efeitos similares em seres humanos (Puttkammer, 1994). Alguns estudos retratam o uso da geleia real atuando no processo reprodutivo de animais. Em coelhos, o tratamento com geleia resultou em melhora da fertilidade e do desenvolvimento embriogênico (Husein e Haddad, 2006).

Husein e Kridli (2002) mostraram que parâmetros reprodutivos, como a resposta ao estro e à taxa de prenhez, melhoraram em ovelhas quando se administrou geleia real associada ao tratamento com progesterona intravaginal. Esses autores verificaram grande proporção de ovelhas em estro, pequenos intervalos para o início do estro e aumento do número de ovelhas gestantes ao primeiro estro. Em outro estudo com ovelhas, Husein e Haddad (2006) utilizaram geleia real em substituição à gonadotrofina coriônica equina (eCG) em protocolos de sincronização de estro e constataram que a geleia real produziu efeitos similares àqueles promovidos pela eCG na resposta aos protocolos de sincronização, no que diz respeito à indução do estro, à taxa de gestação e à taxa de nascimento.

Contudo, estudos que relacionem a geleia real com reprodução de machos são escassos, o que torna imprescindível avaliar os seus efeitos sobre parâmetros morfofisiológicos dos testículos.

Assim, este trabalho teve o objetivo de estudar os efeitos de diferentes doses e de diferentes vias de aplicação de geleia real sobre características morfofisiológicas testiculares de camundongos adultos.

\section{MATERIAL E MÉTODOS}

Foram utilizados 57 camundongos machos (Mus musculus) da linhagem Swiss, com quatro meses de idade. Os animais receberam água e ração comercial ad libitum, específica para animais de laboratório.

Os animais foram distribuídos aleatoriamente em seis tratamentos (T): T1 - administração intraperitoneal de $0,2 \mathrm{~mL}$ de solução fisiológica, diariamente, durante 45 dias $(n=10) ;$ T2 administração intraperitoneal de $0,1 \mathrm{mg}$ de geleia real diluída em $0,2 \mathrm{~mL}$ de água destilada, diariamente, durante 45 dias $(\mathrm{n}=10)$; T3 administração intraperitoneal de $0,2 \mathrm{mg}$ de geleia real diluída em $0,2 \mathrm{~mL}$ de água destilada, diariamente durante 45 dias $(n=8) ; \quad T 4 \quad-$ fornecimento de água destilada sem adição de geleia real (via oral) $(n=10)$; T5 - fornecimento de $0,1 \mathrm{mg}$ de geleia real via oral, diariamente, durante 45 dias, diluída na água de beber dos animais $(\mathrm{n}=10)$; T6 - fornecimento de $0,2 \mathrm{mg}$ de geleia real via oral, diariamente, durante 45 dias, diluída na água de beber $(\mathrm{n}=9)$.

Os animais que receberam administração intraperitoneal de geleia real foram submetidos à contenção física. $\mathrm{O}$ abate ocorreu após 45 dias de suplementação, utilizando-se a técnica de deslocamento cervical.

Após o abate e a pesagem dos animais em balança analítica de precisão, fez-se a abertura da cavidade abdominal para retirada dos testículos. Os órgãos coletados, separados em direito e esquerdo, foram colocados em recipientes com formol $10 \%$ tamponado. Após o período de fixação de 24 horas, os testículos foram pesados e transferidos para um recipiente com álcool $70 \%$. O material histológico foi desidratado em passagens por soluções de concentrações crescentes de álcool etílico $(80 \%, 90 \%, 95 \%$ e absoluto), diafanizado em xilol e posteriormente incluído em parafina. Cortes de quatro micrômetros de espessura, obtidos em micrótomo rotativo ${ }^{1}$, foram montados sobre lâmina de vidro e corados com hematoxilina de Harris e eosina (Luna, 1968).

${ }^{1}$ Reichert-jung 2045 Multicut, Alemanha. 
Após a preparação dos cortes histológicos, mensurou-se o diâmetro médio dos túbulos seminíferos a partir de 20 secções transversais por animal, independente do estádio do ciclo do epitélio seminífero em que suas células se encontravam. As secções foram escolhidas ao acaso, mediante varredura horizontal, sendo utilizadas aquelas que apresentavam o contorno o mais circular possível. As mensurações foram feitas com o auxílio de ocular micrométrica 10x e objetiva de 10x em microscópio óptico.

Na mesma secção em que foi obtido o diâmetro tubular, mensurou-se a altura do epitélio seminífero, considerando-se a espessura epitelial desde a membrana basal até a borda luminal. Duas mensurações foram obtidas de cada secção transversal, referente a dois pontos contralaterais, sendo considerado como medida representativa a média entre as duas mensurações.

Para o cálculo da proporção volumétrica dos componentes do parênquima testicular, foi utilizada uma gratícula com 408 intercessões consideradas como pontos. Foram examinados cinco campos, escolhidos ao acaso, por meio de varredura horizontal dos cortes. Em cada animal, foram computados os pontos coincidentes sobre os diferentes elementos constituintes do parênquima testicular. As proporções volumétricas, descritas em percentagem, foram calculadas sobre um total de 2040 pontos por animal, em aumento de 400x. Os componentes do parênquima testicular registrados foram: túbulo seminífero (túnica própria, epitélio seminífero, lume tubular), células intersticiais de Leydig, vasos sanguíneos e linfáticos e tecido conjuntivo.

Para o cálculo do volume do parênquima testicular, foram descontados $7,5 \%$ do peso dos testículos, referentes ao percentual ocupado pela túnica albugínea e mediastino. Como a densidade dos testículos é muito próxima de 1, seu peso foi considerado como volume (Paula, 1999). A partir do volume do parênquima, calcularam-se o percentual ocupado pelos túbulos seminíferos, o espaço intertubular e as células de Leydig no parênquima testicular.

Para calcular o comprimento total dos túbulos seminíferos, foi utilizada a fórmula: CTT = $\mathrm{vts} / \pi \mathrm{r}^{2}$, em que: CTT é o comprimento total dos túbulos seminíferos, vts é o volume total dos túbulos seminíferos, calculado anteriormente pela proporção volumétrica de túbulos seminíferos no volume testicular, e $\pi r^{2}$ é a área da base correspondente à área da secção transversal do túbulo seminífero, sendo considerado o raio (r) metade do diâmetro médio. $\mathrm{O}$ resultado final, referente ao comprimento total de túbulos, para cada animal, foi expresso em metros.

$\mathrm{O}$ índice gonadossomático, que representa o percentual da massa corporal alocado em testículo, foi calculado a partir do peso médio dos dois testículos dividido pelo peso corporal. Os índices leydigossomático e tubulossomático representam o percentual da massa corporal alocados, respectivamente, em células de Leydig e em túbulos seminíferos. Foram calculados inferindo-se ao índice gonadossomático o percentual do parênquima testicular ocupado pelas células de Leydig e túbulos seminíferos.

Utilizou-se o teste estatístico Kruskall Wallis, com nível de significância de $5 \%$, para a análise dos parâmetros e, a posteriori, o teste U, de Mann-Whitney.

\section{RESULTADOS E DISCUSSÃO}

Os resultados para peso corporal, peso médio dos testículos e índice gonadossomático encontramse na Tab. 1. Não houve diferença entre os tratamentos $(\mathrm{P}>0,05)$.

Estes resultados assemelham-se aos observados por Kridli et al. (2003) e Kridli e Al-Khetib (2006), que não encontraram diferença no peso corporal médio de ovelhas entre os tratamentos suplementados ou não com geleia real. Também não se observou diferença no peso dos testículos e no índice gonadossomático entre os tratamentos $(\mathrm{P}>0,05)$. Isso mostra que $\mathrm{o}$ percentual de massa corporal alocado nos testículos foi similar para os seis tratamentos.

Os valores do diâmetro tubular e da altura do epitélio seminífero e seus respectivos desviospadrão encontram-se na Tab. 2. 
Tabela 1. Peso corporal, peso testicular e índice gonadossomático de camundongos suplementados com geleia real por via oral ou intraperitoneal

\begin{tabular}{cccc}
\hline Tratamento & PC $(\mathrm{g})$ & PT $(\mathrm{g})$ & IGS $(\%)$ \\
\hline T1 $(\mathrm{n}=10)$ & $40,62 \pm 3,47$ & $0,28 \pm 0,02$ & $0,69 \pm 0,07$ \\
T2 $(\mathrm{n}=10)$ & $41,25 \pm 1,86$ & $0,28 \pm 0,03$ & $0,68 \pm 0,06$ \\
T3 $(\mathrm{n}=08)$ & $45,16 \pm 4,91$ & $0,24 \pm 0,04$ & $0,53 \pm 0,12$ \\
T4 $(\mathrm{n}=10)$ & $42,50 \pm 4,91$ & $0,28 \pm 0,04$ & $0,66 \pm 0,11$ \\
T5 $(\mathrm{n}=10)$ & $40,07 \pm 4,49$ & $0,26 \pm 0,03$ & $0,66 \pm 0,10$ \\
T6 $(\mathrm{n}=09)$ & $45,39 \pm 5,74$ & $0,27 \pm 0,03$ & $0,62 \pm 0,13$ \\
\hline
\end{tabular}

T1: solução fisiológica, via intraperitoneal; T2: $0,1 \mathrm{mg}$ de geleia real, via intraperitoneal; T3: $0,2 \mathrm{mg}$ de geleia real, via intraperitoneal; T4: água destilada, via oral; T5: 0,1mg de geleia real, via oral; T6: 0,2mg de geleia real, via oral. $\mathrm{PC}=$ peso corporal; $\mathrm{PT}=$ peso testicular; IGS= índice gonadossomático.

Valores nas colunas não diferem entre si, pelo teste Kruskal-Wallis $(\mathrm{P}>0,05)$.

Tabela 2. Valores médios e desvio-padrão do diâmetro dos túbulos seminíferos e da altura do epitélio seminífero de testículos de camundongos suplementados com geleia real por via oral ou intraperitoneal

\begin{tabular}{ccc}
\hline Tratamento & DTS $(\mu \mathrm{m})$ & AES $(\mu \mathrm{m})$ \\
\hline T1 $(\mathrm{n}=10)$ & $192,95 \pm 13,54$ & $60,48 \pm 4,04$ \\
T2 $(\mathrm{n}=10)$ & $183,40 \pm 14,04$ & $61,50 \pm 5,46$ \\
T3 $(\mathrm{n}=08)$ & $190,81 \pm 9,98$ & $58,31 \pm 3,60$ \\
T4 $(\mathrm{n}=10)$ & $188,95 \pm 25,0$ & $56,58 \pm 11,10$ \\
T5 $(\mathrm{n}=10)$ & $194,45 \pm 10,84$ & $58,60 \pm 6,62$ \\
T6 $(\mathrm{n}=09)$ & $197,39 \pm 13,37$ & $57,00 \pm 5,09$ \\
\hline
\end{tabular}

T1: solução fisiológica, via intraperitoneal; T2: 0,1mg de geleia real, via intraperitoneal; T3: 0,2mg de geleia real, via intraperitoneal; T4: água destilada, via oral; T5: $0,1 \mathrm{mg}$ de geleia real, via oral; T6: 0,2mg de geleia real, via oral. DTS= diâmetro do túbulo seminífero; $\mathrm{AES}=$ altura do epitélio seminífero.

Valores nas colunas não diferem entre si pelo teste Kruskal-Wallis $(\mathrm{P}>0,05)$.

Os valores referentes ao diâmetro tubular não diferiram entre os grupos $(\mathrm{P}>0,05)$ e se enquadraram dentro do valor do diâmetro tubular médio tipicamente observado para a maioria dos mamíferos, que varia de 180 a $300 \mu \mathrm{m}$ (França e Russell, 1998). Neste estudo, o menor valor foi de $183,40 \mu \mathrm{m}$ e o maior, de $197,39 \mu \mathrm{m}$. Em pesquisas que envolvem a função testicular, a medida do diâmetro tubular é uma abordagem classicamente utilizada para indicar a atividade espermatogênica (Paula, 1999; Moura et al., 2006).

Diversos fatores contribuem para a constituição do diâmetro tubular e a altura do epitélio seminífero, como o número de camadas de células mioides, que constituem a túnica própria, o tamanho e a população das células de Sertoli e das células germinativas e a secreção de fluido pelas células de Sertoli. Esses fatores podem variar bastante entre as diferentes espécies de mamíferos e entre raças e linhagens, dentro de uma mesma espécie (Paula, 1999).
Outro fator que pode ser levado em consideração é a retração linear que ocorre nos tecidos devido ao tipo de inclusão utilizada durante o processamento histológico (Costa, 2001). Essa retração pode compreender $15 \%$ em inclusões em parafina, com as utilizadas neste estudo, e de 3 a 5\% para fragmentos testiculares incluídos em resina plástica. Estes fatores podem explicar a grande amplitude observada para o diâmetro dos túbulos seminíferos entre as espécies (Paula, 1999).

Não houve diferença na altura do epitélio seminífero entre os tratamentos $(\mathrm{P}>0,05)$. Esses valores encontram-se dentro ou bem próximo da amplitude média referente à maioria dos mamíferos, que é de 60 a $100 \mu \mathrm{m}$ (França e Russell, 1998). Por ser mais influenciada pelo peristaltismo tubular que por variações metodológicas, é, provavelmente, um parâmetro melhor que o diâmetro tubular para avaliação da atividade espermatogênica (Paula, 1992). Como não houve diferença significativa entre essas duas características, pode-se sugerir que os 
fatores que contribuem para a constituição desses parâmetros, como o número de camadas de células mioides que constituem a túnica própria, o tamanho e a população das células de Sertoli e células germinativas, não sofreram alterações significativas dentro de cada tratamento.
As médias e desvios-padrão da proporção volumétrica dos componentes do parênquima testicular, referentes aos compartimentos tubular e intertubular, e o volume dos componentes principais do parênquima testicular encontram-se nas Tab. 3, 4 e 5, respectivamente.

Tabela 3. Proporção volumétrica dos componentes do parênquima testicular, referentes ao compartimento tubular, de camundongos suplementados com geleia real por via oral e via intraperitoneal

\begin{tabular}{ccccc}
\hline Tratamento & TP $(\%)$ & ES $(\%)$ & L $(\%)$ & TS $(\%)$ \\
\hline T1 $(n=5)$ & $6,58 \pm 2,57$ & $69,52 \pm 4,71$ & $18,04 \pm 7,92$ & $94,14 \pm 1,77 \mathrm{a}$ \\
T2 $(\mathrm{n}=5)$ & $6,62 \pm 1,81$ & $76,14 \pm 4,70$ & $8,45 \pm 2,63$ & $91,21 \pm 4,08 \mathrm{ab}$ \\
T3 $(\mathrm{n}=5)$ & $4,80 \pm 1,50$ & $70,80 \pm 3,37$ & $12,41 \pm 3,42$ & $88,02 \pm 1,65 \mathrm{~b}$ \\
T4 $(\mathrm{n}=5)$ & $4,89 \pm 0,49$ & $75,66 \pm 3,88$ & $8,20 \pm 2,72$ & $88,75 \pm 3,59 \mathrm{ab}$ \\
T5 $(\mathrm{n}=5)$ & $5,52 \pm 0,83$ & $74,03 \pm 3,67$ & $12,22 \pm 2,52$ & $91,77 \pm 2,47 \mathrm{ab}$ \\
T6 $(\mathrm{n}=5)$ & $5,14 \pm 0,65$ & $73,68 \pm 2,82$ & $12,25 \pm 3,67$ & $91,06 \pm 3,11 \mathrm{ab}$ \\
\hline
\end{tabular}

T1: solução físiológica, via intraperitoneal; T2: $0,1 \mathrm{mg}$ de geleia real, via intraperitoneal; T3: $0,2 \mathrm{mg}$ de geleia real, via intraperitoneal; T4: água destilada, via oral; T5: 0,1mg de geleia real, via oral; T6: 0,2mg de geleia real, via oral. TP= túnica própria, $\mathrm{ES}=$ epitélio seminífero, $\mathrm{L}=$ lume tubular, $\mathrm{TS}=$ túbulo seminífero.

Valores seguidos por letras diferentes na coluna diferem entre si pelo teste Kruskal-Wallis $(\mathrm{P}<0,05)$.

A proporção volumétrica dos componentes do parênquima testicular de mamíferos varia bastante entre as espécies, principalmente os percentuais referentes aos túbulos seminíferos e às células de Leydig (França e Russell, 1998).

Os valores médios referentes à proporção da túnica própria e ao epitélio seminífero (Tab. 3), no testículo dos camundongos, não diferiram entre os tratamentos $(\mathrm{P}>0,05)$. Este resultado relaciona-se, de forma positiva, com o diâmetro tubular, no qual ambas as variáveis não sofreram alterações em relação às doses de geleia real e às duas vias de administração.
Os valores referentes aos túbulos seminíferos (Tab. 3) estão dentro dos encontrados para alguns roedores, de 30\% para a marmota (Russell et al., 1990), de 42\% para a capivara (Paula, 1999) e de 93\% para o degu (Russell et al., 1990). Entretanto, houve diferença entre T1 e T3 $(\mathrm{P}<0,05)$, isto é, o $\mathrm{T} 1$ apresentou maior proporção de túbulos seminíferos em relação ao T3. Esse fato apresenta relação direta com a proporção volumétrica ocupada pelo intertúbulo no testículo dos animais, no qual os animais do T1 apresentaram maior investimento em túbulos seminíferos quando comparado com seu espaço intertubular.

Tabela 4. Proporção volumétrica dos componentes do parênquima testicular, referentes ao compartimento intertubular, de camundongos suplementados com geleia real por via oral e via intraperitoneal

\begin{tabular}{cccccc}
\hline Tratamento & CL $(\%)$ & VS $(\%)$ & VL $(\%)$ & C $(\%)$ & EI $(\%)$ \\
\hline T1 $(n=5)$ & $2,12 \pm 1,14 \mathrm{a}$ & $0,25 \pm 0,12$ & $0,08 \pm 0,08$ & $3,42 \pm 1,97$ & $5,86 \pm 1,77 \mathrm{a}$ \\
T2 $(\mathrm{n}=5)$ & $3,79 \pm 1,07 \mathrm{ab}$ & $0,48 \pm 0,80$ & $0,04 \pm 0,02$ & $4,48 \pm 2,56$ & $8,79 \pm 4,08 \mathrm{ab}$ \\
T3 $(\mathrm{n}=5)$ & $4,01 \pm 0,85 \mathrm{~b}$ & $0,42 \pm 0,08$ & $0,17 \pm 0,07$ & $7,38 \pm 1,61$ & $11,98 \pm 1,65 \mathrm{~b}$ \\
T4 $(\mathrm{n}=5)$ & $2,92 \pm 1,26 \mathrm{ab}$ & $1,00 \pm 0,81$ & $0,12 \pm 0,06$ & $7,22 \pm 2,06$ & $11,25 \pm 3,59 \mathrm{ab}$ \\
T5 $(\mathrm{n}=5)$ & $2,55 \pm 0,39 \mathrm{ab}$ & $0,33 \pm 0,29$ & $0,14 \pm 0,10$ & $5,21 \pm 2,34$ & $8,23 \pm 2,47 \mathrm{ab}$ \\
T6 $(\mathrm{n}=5)$ & $2,14 \pm 0,84 \mathrm{ab}$ & $0,33 \pm 0,11$ & $0,10 \pm 0,08$ & $6,37 \pm 2,17$ & $8,94 \pm 3,11 \mathrm{ab}$ \\
\hline
\end{tabular}

T1: solução fisiológica, via intraperitoneal; T2: $0,1 \mathrm{mg}$ de geleia real, via intraperitoneal; T3: $0,2 \mathrm{mg}$ de geleia real, via intraperitoneal; T4: água destilada, via oral; T5: $0,1 \mathrm{mg}$ de geleia real, via oral; T6: $0,2 \mathrm{mg}$ de geleia real, via oral. $\mathrm{CL}=$ célula de Leydig; $\mathrm{VS}=$ vaso sanguíneo; $\mathrm{VL}=$ vaso linfático; $\mathrm{C}=$ conjuntivo; $\mathrm{EI}=$ espaço intertubular. Valores seguidos por letras diferentes na coluna diferem entre si pelo teste Kruskal-Wallis $(\mathrm{P}<0,05)$. 
Tabela 5. Volume dos componentes principais do parênquima testicular de camundongos suplementados com geleia real por via oral e via intraperitoneal

\begin{tabular}{ccccc}
\hline Tratamento & VPT $(\mathrm{mL})$ & VTS $(\mathrm{mL})$ & VEI $(\mathrm{mL})$ & VCL $(\mathrm{mL})$ \\
\hline T1 $(\mathrm{n}=5)$ & $0,13 \pm 0,01 \mathrm{~b}$ & $0,12 \pm 0,01$ & $0,008 \pm 0,002$ & $0,003 \pm 0,002$ \\
T2 $(\mathrm{n}=5)$ & $0,14 \pm 0,01 \mathrm{~b}$ & $0,12 \pm 0,01$ & $0,012 \pm 0,007$ & $0,005 \pm 0,002$ \\
T3 $(\mathrm{n}=5)$ & $0,17 \pm 0,07 \mathrm{a}$ & $0,15 \pm 0,06$ & $0,020 \pm 0,008$ & $0,007 \pm 0,004$ \\
T4 $(\mathrm{n}=5)$ & $0,14 \pm 0,03 \mathrm{~b}$ & $0,12 \pm 0,02$ & $0,015 \pm 0,005$ & $0,004 \pm 0,001$ \\
T5 $(\mathrm{n}=5)$ & $0,12 \pm 0,02 \mathrm{~b}$ & $0,11 \pm 0,02$ & $0,009 \pm 0,002$ & $0,003 \pm 0,0005$ \\
T6 $(\mathrm{n}=5)$ & $0,13 \pm 0,01 \mathrm{~b}$ & $0,12 \pm 0,01$ & $0,012 \pm 0,003$ & $0,003 \pm 0,001$
\end{tabular}

T1: solução fisiológica, via intraperitoneal; T2: 0,1mg de geleia real, via intraperitoneal; T3: 0,2mg de geleia real, via intraperitoneal; T4: água destilada, via oral; T5: 0,1mg de geleia real, via oral; T6: 0,2mg de geleia real, via oral. $\mathrm{VPT}=$ volume do parênquima testicular; VTS $=$ volume dos túbulos seminíferos; $\mathrm{VEI}=$ volume do espaço intertubular; $\mathrm{VCL}=$ volume das células de Leydig.

Valores seguidos por letras diferentes na coluna diferem entre si $(\mathrm{P}<0,05)$.

Na maioria das espécies, o túbulo seminífero é o principal componente do parênquima testicular, sendo responsável pela gametogênese. Nesse sentido, a massa testicular reflete diretamente a produção espermática. A variação encontrada nas diversas espécies, referente à proporção de túbulos seminíferos, pode ser considerada como um dos principais fatores responsáveis pela diferença observada na eficiência da produção espermática dessas espécies (França e Russell, 1998).

Os valores encontrados para a proporção volumétrica de vasos sanguíneos e vasos linfáticos não diferiram entre os tratamentos $(\mathrm{P}>0,05)$ (Tab. 4).

Neste estudo, o tecido conjuntivo não se refere apenas ao tecido, mas também às células do tecido conjuntivo, nervos, fibras e espaços linfáticos. Isso pode explicar os valores relativamente altos para esse componente do tecido intertubular, quando correlacionado com a organização dos elementos do espaço intertubular, pois, devido ao fato de a proporção volumétrica variar, na maioria das espécies estudadas, foi descrito o arranjo e a proporção dos elementos constituintes do espaço intertubular, agrupando as espécies em três padrões distintos. $\mathrm{O}$ rato, o camundongo, o hamster, o porco-da-índia e a chinchila apresentam organização do tipo I, em que as células de Leydig e o tecido conjuntivo ocupam uma área muito pequena no compartimento intertubular, contrastando com extensos espaços linfáticos interpostos aos túbulos seminíferos (Fawcett et al., 1973).

As células de Leydig são as principais responsáveis pela produção de esteroides. Contudo, uma grande variação é observada no percentual ocupado por essas células no tecido intertubular dos diferentes animais (Costa et al., 2006). Observou-se diferença na proporção de células de Leydig no testículo dos camundongos entre T1 e T3 $(\mathrm{P}<0,05)$ (Tab. 4). O aumento significativo dessas células no intertúbulo dos animais do T3 poderia estar correlacionado com o aumento da concentração de testosterona. Entretanto, como não foi realizada coleta de sangue para análise de testosterona, essa correlação não pôde ser estimada. Correlação positiva entre o número total de células de Leydig no testículo e a concentração de testosterona foi anteriormente encontrada em coelhos (Castro et al., 2002).

A proporção volumétrica ocupada pelo espaço intertubular reduziu-se do T3 para T1. Sabe-se que há relação entre a proporção de túbulos seminíferos e o espaço intertubular; desse modo, se há um investimento maior no espaço intertubular, há diminuição da proporção de túbulos seminíferos.

Observou-se diferença no volume do parênquima testicular entre os tratamentos $(\mathrm{P}<0,05$; Tab. 5). Como esse volume está diretamente relacionado ao peso testicular, pode-se inferir que, nos testículos dos animais do T3, o parênquima testicular ocupou maior volume em relação aos 
testículos dos animais dos outros tratamentos. Esse fato pode estar relacionado ao maior volume ocupado pelo espaço intertubular no parênquima e, consequentemente, ao volume ocupado pelas células de Leydig no espaço intertubular.

Não houve diferença no volume ocupado pelos túbulos seminíferos no parênquima testicular entre os tratamentos $(\mathrm{P}>0,05)$.

Segundo Russell e França (1995), a variação de valores referentes à proporção volumétrica e ao volume dos componentes testiculares tem relativamente poucas causas, como: fixação do órgão e retração linear tecidual provocadas pelo fixador; técnicas morfométricas utilizadas pelos pesquisadores; total de amostras utilizadas pelos pesquisadores; e interpretação de micrografias, de qualidade variável, que pode levar a diferenças nos resultados, principalmente se for acompanhada por uma fixação ruim. Todos esses fatores contribuem para que haja grande variação nos dados da literatura, o que dificulta comparar os trabalhos que envolvem principalmente estudos toxicológicos.

As médias e desvios-padrão do comprimento total de túbulos seminíferos e comprimento de túbulos por grama de testículo e os índices leydigossomático e tubulossomático encontramse na Tab. 6.

Tabela 6. Índices leydigossomático, tubulossomático, comprimento total dos túbulos seminíferos e comprimento de túbulos por grama de testículo dos camundongos suplementados com geleia real por via oral e via intraperitoneal

\begin{tabular}{ccccc}
\hline Tratamento & ILS $(\%)$ & ITS $(\%)$ & CTT $(\mathrm{m})$ & CTGT $(\mathrm{m} / \mathrm{g})$ \\
\hline T1 $(\mathrm{n}=5)$ & $0,007 \pm 0,004$ & $0,30 \pm 0,04$ & $4,01 \pm 0,45$ & $14,32 \pm 1,18$ \\
T2 $(\mathrm{n}=5)$ & $0,012 \pm 0,004$ & $0,30 \pm 0,01$ & $4,99 \pm 0,67$ & $16,93 \pm 0,70$ \\
T3 $(\mathrm{n}=5)$ & $0,017 \pm 0,010$ & $0,35 \pm 0,18$ & $5,44 \pm 2,39$ & $23,52 \pm 8,40$ \\
T4 $(\mathrm{n}=5)$ & $0,010 \pm 0,004$ & $0,30 \pm 0,06$ & $4,81 \pm 2,31$ & $16,82 \pm 8,78$ \\
T5 $(\mathrm{n}=5)$ & $0,008 \pm 0,001$ & $0,29 \pm 0,07$ & $3,70 \pm 0,38$ & $15,13 \pm 1,35$ \\
T6 $(\mathrm{n}=5)$ & $0,006 \pm 0,001$ & $0,26 \pm 0,03$ & $4,03 \pm 0,38$ & $14,12 \pm 1,41$ \\
\hline
\end{tabular}

T1: solução fisiológica, via intraperitoneal; T2: $0,1 \mathrm{mg}$ de geleia real, via intraperitoneal; T3: 0,2mg de geleia real, via intraperitoneal; T4: água destilada, via oral; T5: 0,1mg de geleia real, via oral; T6: 0,2mg de geleia real, via oral. ILS= índice leydigossomático; ITS= índice tubulossomático; CTT= comprimento total dos túbulos seminíferos; CTGT $=$ comprimento de túbulos por grama de testículo.

Valores nas colunas não diferem entre si $(\mathrm{P}>0,05)$.

Não houve diferença no comprimento total dos túbulos seminíferos entre os tratamentos $(\mathrm{P}>0,05)$. Essa é uma variável diretamente dependente do volume total dos túbulos e do diâmetro tubular, ou seja, diretamente relacionada ao tamanho do testículo (Souza et al., 2005). Entretanto, uma comparação entre diferentes espécies quanto ao comprimento de túbulos não é uma abordagem significativa, devido à grande variação encontrada para o tamanho testicular. Dessa forma, o comprimento tubular por grama de testículo é um parâmetro mais seguro para a comparação entre as espécies (Leite, 2002).

Os valores médios do comprimento de túbulos seminíferos por grama de testículo dos camundongos não variaram estatisticamente e permaneceram dentro ou bem próximo da média encontrada para os mamíferos, que é de 10 a 15 metros (França e Russell, 1998).

O índice tubulossomático relaciona-se com o volume de túbulos seminíferos no testículo, por isso não se observou diferença entre os tratamentos para essa característica $(\mathrm{P}>0,05)$. Esse índice é um parâmetro proposto para que se possa quantificar o investimento percentual corporal em túbulos seminíferos, possibilitando, assim, a comparação intra e interespecífica em animais de tamanho corporal diferente (Leite, 2002).

Para o índice leydigossomático, que representa o percentual de massa corporal alocado em células de Leydig, não houve diferença significativa entre os tratamentos $(\mathrm{P}>0,05)$. Os valores desse parâmetro apresentaram-se abaixo dos 
encontrados em roedores, como o porco-da-índia $(0,044 \%)$, o camundongo $(0,030 \%)$, o rato $(0,055 \%)$ (Russell (1996), citado por Costa et al. (2006) e a capivara $0,037 \%$ (Costa et al., 2006). Entretanto, os valores desse índice estão bem próximos ao encontrado por Souza et al. (2005), que utilizaram nandrolona em ratos Wistar $(0,007-0,019 \%)$. Dessa maneira, pode-se inferir que o percentual de massa corporal alocado em células de Leydig e túbulos seminíferos foi semelhante nos tratamentos, independente da dosagem de geleia real e da sua via de administração.

Nas condições em que foi realizado o experimento, conclui-se que a suplementação com geleia real na dose de $0,2 \mathrm{mg}$ diária, por reduzir a proporção volumétrica de túbulos seminíferos, pode refletir negativamente na produção espermática de camundongos. Contudo, o aumento na proporção volumétrica de células de Leydig apresentado por eles pode refletir em maior concentração de andrógenos e compensar a diminuição tubular.

\section{REFERÊNCIAS BIBLIOGRÁFICAS}

CASTRO, A.C.S.; BERNDTSON, W.E.; CARDOSO, F.M. Plasma and testicular testosterone levels, volume density and number of Leydig cells and spermatogenic efficiency of rabbits. Braz. J. Med. Biol. Res., v.35, p.493-498, 2002.

COSTA, D.S. Análise morfofuncional da espermatogênese e características seminais de Catetos (Tayassu tajacu). 2001. 61f. Tese (Doutorado) - Escola de Veterinária, Universidade Federal de Minas Gerais, Belo Horizonte.

COSTA, D.S.; PAULA, T.A.R.; MATTA, S.L.P. The intertubular compartment morphometry in capybaras (Hidrochoerus hidrochaeris). Anim. Reprod. Sci., v.91, p.173-179, 2006.

FAWCETT, D.W.; NEAVES, W.B.; FLORES, M.N. Comparative observations on intertubular lymphatic and the organization of the interstitial tissue of the mammalian testis. Biol. Reprod., v.9, p.500-532, 1973.

FRANÇA, L.R.; RUSSELL, L.D. The testis of domestic animals. In: REGADERA, J.; MARTINEZ-GARCIA, F. (Eds). Male reproduction: A multidisciplinary overview. Madrid: Churchill Livingstone, 1998. p.197-219.

HUSEIN, M.Q.; HADDAD, S.G. A new approach to enhance reproductive performance in sheep using royal jelly in comparison with equine chorionic gonadotropin. Anim. Reprod. Sci., v.93, p.24-33, 2006.

HUSEIN, M.Q.; KRIDLI, R.T. Reproductive responses following royal jelly treatment administered orally or intramuscularly into progesterone-treated Awassi ewes. Anim. Reprod. Sci., v.74, p.45-53, 2002.

KOHNO, K.; OKAMOTO, I.; SANO, O. et al. Royal jelly inhibits the production of proinflammatory cytokines by activated macrophages. Biosci. Biotechnol. Biochem., v.68, p.138-145, 2004.

KRIDLI, R.T.; AL-KHETIB, S.S. Reproductive responses in ewes treated with eCG or increasing doses of royal jelly. Anim. Reprod. Sci., v.92, p.75-85, 2006

KRIDLI, R.T.; HUSEIN, M.Q.; HUMPHREY, W.D. Effect of royal jelly and GnRH on the estrus synchronization and pregnancy rate in ewes using intravaginal sponges. Small Rum. Res., v.49, p.25-30, 2003.

LEITE, F.L.G. Análise morfofuncional do testículo e do processo espermatogênico da onça parda (Puma concolor, Wozencraft, 1993) adulta. 2002. 68f. Dissertação (Mestrado) Universidade Federal de Viçosa, Viçosa.

LENGLER, S. Apicultura - produtos, manejo, nutrição e sanidade. 2.ed. Santa Maria: UFSM, 1999.

LUNA, L.G. Manual of histology stainig methods of the Armed Forces Institute of Pathology. 3.ed. New York: McGraw-Hill, 1968. p.258,

MOURA, C.S.; GUERRA, M.P.P.; SILVA JÚNIOR, V.A. et al. Avaliação histomorfométrica do parênquima testicular de ratos adultos tratados com diferentes doses de ivermectina. Arq. Bras. Med. Vet. Zootec., v.58, p.799-808, 2006.

PAMPLONA, L.C.; AZEDO, R.A.B.; OLIVEIRA, K.C.L.S. et al. Physicochemical analyses indicated to the quality control of royal jelly with honey. Cienc. Tecnol. Alim., v.24, p.608-612, 2004. 
PAULA, T.A.R. Avaliação histológica e funcional do testículo de capivaras adultas (Hydrochoerus hydrochaeris). 1999. 84f. Tese (Doutorado) - Instituto de Ciências Biológicas, Universidade Federal de Minas Gerais, Belo Horizonte.

PAULA, T.A.R. Estudo histológico quantitativo da atividade espermatogênica de cães SRD em diferentes faixas etárias após a puberdade. 1992. 62f. Dissertação (Mestrado) - Instituto de Ciências Biológicas, Universidade Federal de Minas Gerais, Belo Horizonte.

PUTTKAMMER, E. Geleia real: métodos e técnicas de produção, coleta e armazenamento. Florianópolis: EPAGRI, 1994. p.30.

RUSSELL, L.D.; FRANÇA, L.R. Building a testis. Tissue Cell, v.27, p.129-147, 1995.
RUSSELL, L.D. Mammalian Leydig cell structure. In: PAYNE, A.H.; HARDY, M.P.; RUSSELL, L.D. (Eds). Viena: Cache River, 1996.

RUSSELL, L.D.; REN, R.A.; SINHA-HIKIN, I. et al. A comparative study in twelve mammalian species of volume densities, volumes and numerical densities of selected testis components, emphasizing those related to the Sertoli cell. Am. J. Anat., v.188, p.21-30, 1990.

SOUZA, P.C.; PAULA, T.A.R.; NATALI, A.J. et al. Efeito do exercício crônico voluntário e do sedentarismo, com e sem o uso do esteroide anabólico nandrolona, sobre os componentes do parênquima testicular de ratos adultos. Rev. Ceres, v.300, p.305-316, 2005. 